Supplement of Hydrol. Earth Syst. Sci., 24, 655-672, 2020

https://doi.org/10.5194/hess-24-655-2020-supplement

(C) Author(s) 2020. This work is distributed under

the Creative Commons Attribution 4.0 License.

(c) (1)

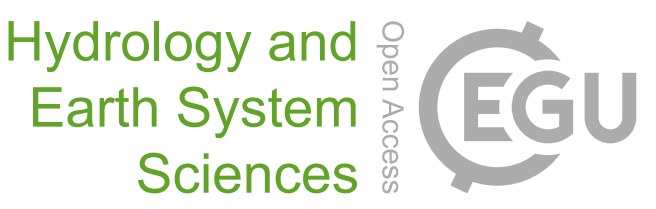

Supplement of

\title{
Modeling groundwater responses to climate change in the Prairie Pothole Region
}

Zhe Zhang et al.

Correspondence to: Yanping Li (yanping.li@usask.ca)

The copyright of individual parts of the supplement might differ from the CC BY 4.0 License. 


\section{Supplemental Materials - WTD dynamics from 33 groundwater wells in the PPR}

WTD dynamics from observational wells and CTRL model with default soil (DEF, blue lines) and replacing default soil with sandy soil (REP, red lines) for the 33 sites in the PPR.

Alberta Environment and Parks
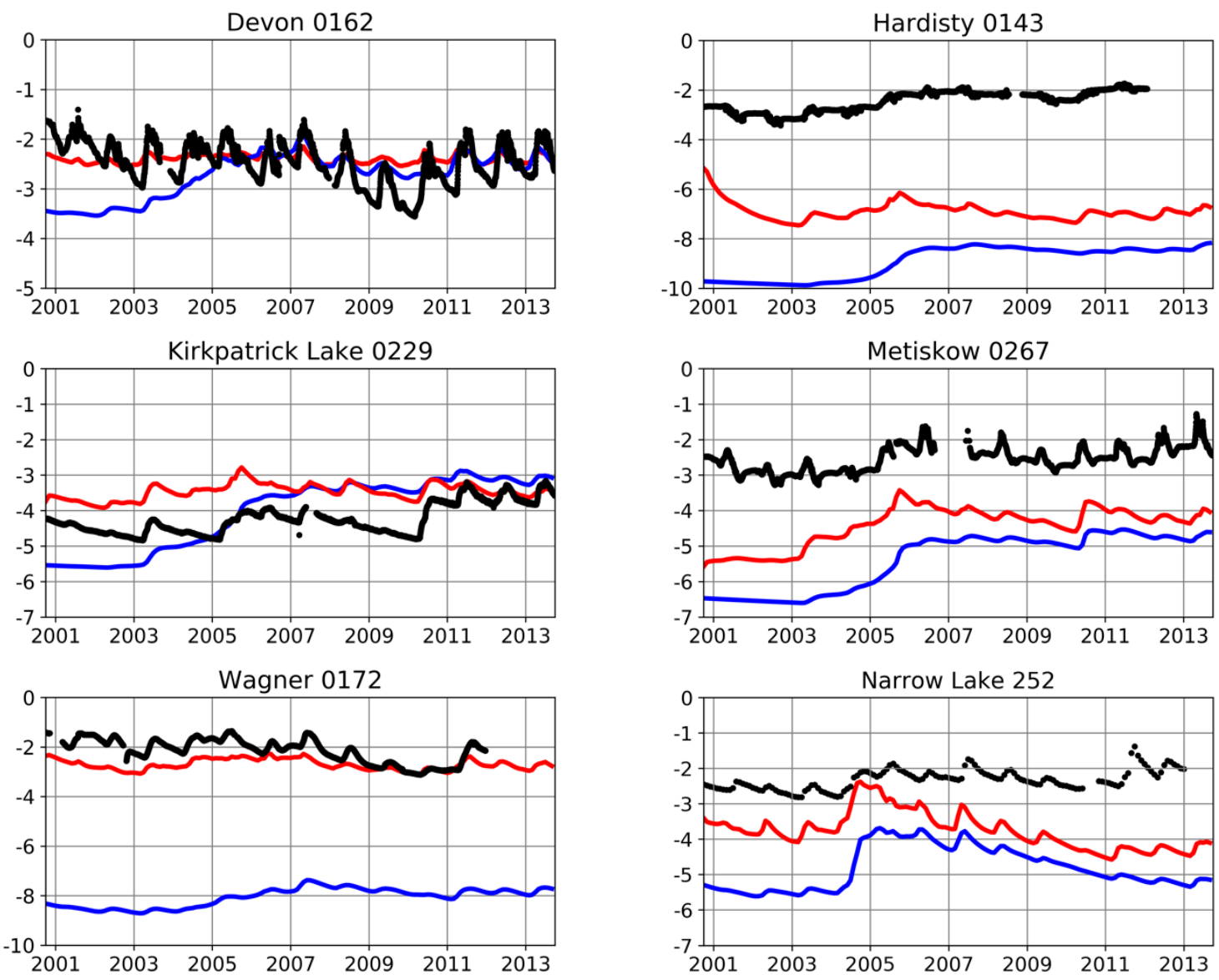
Saskatchewan Water Securtiy Agency
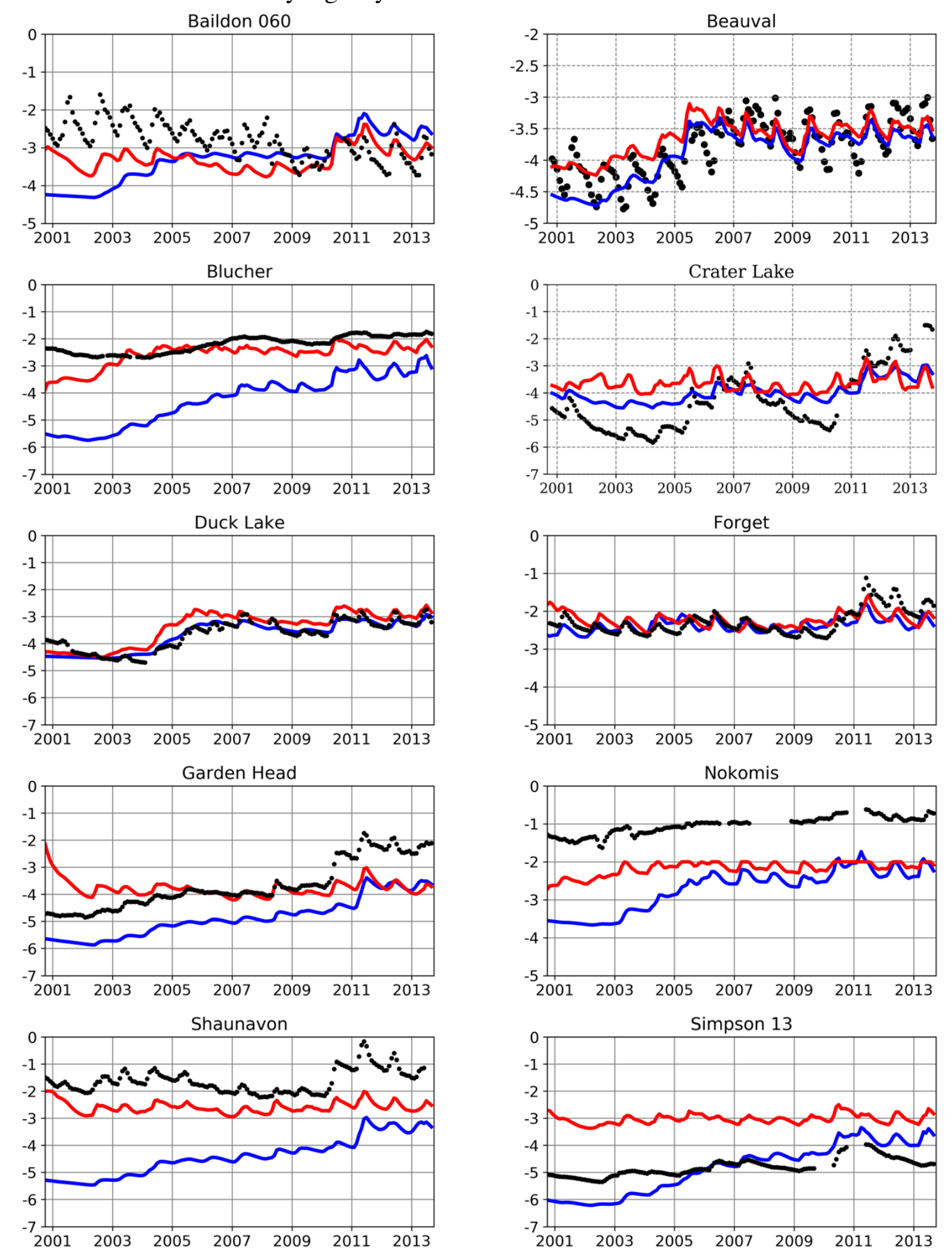

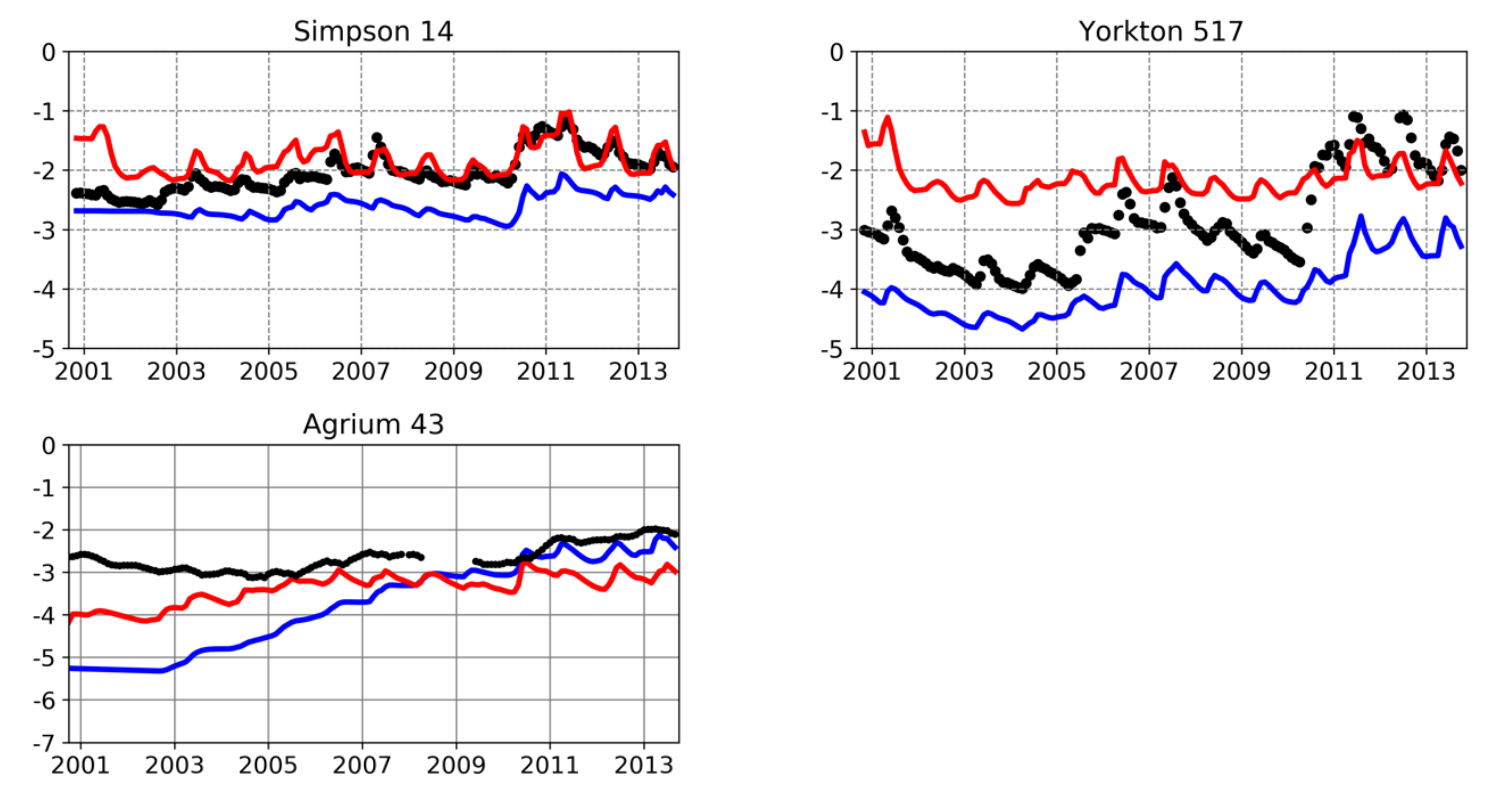
USGS
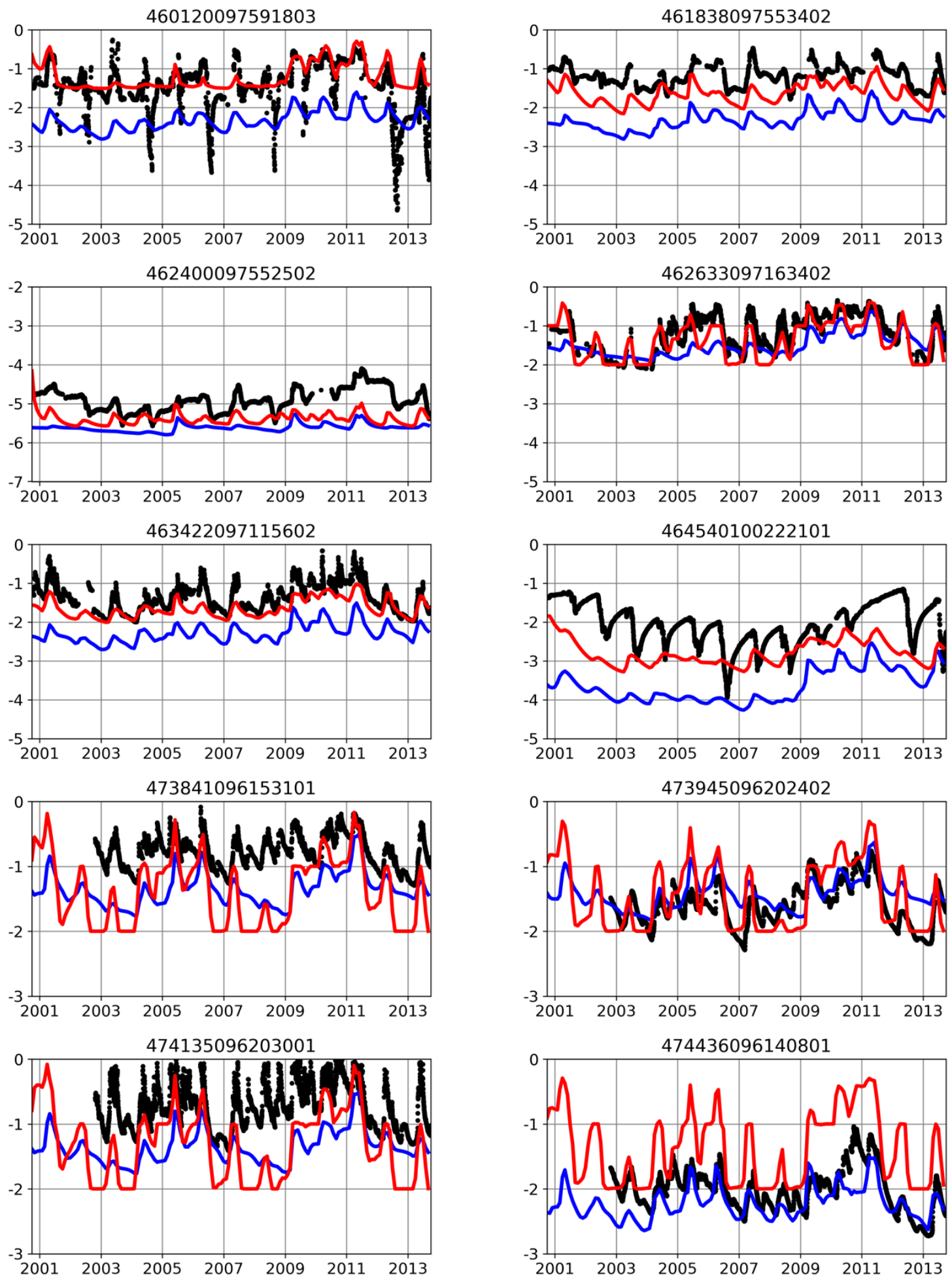

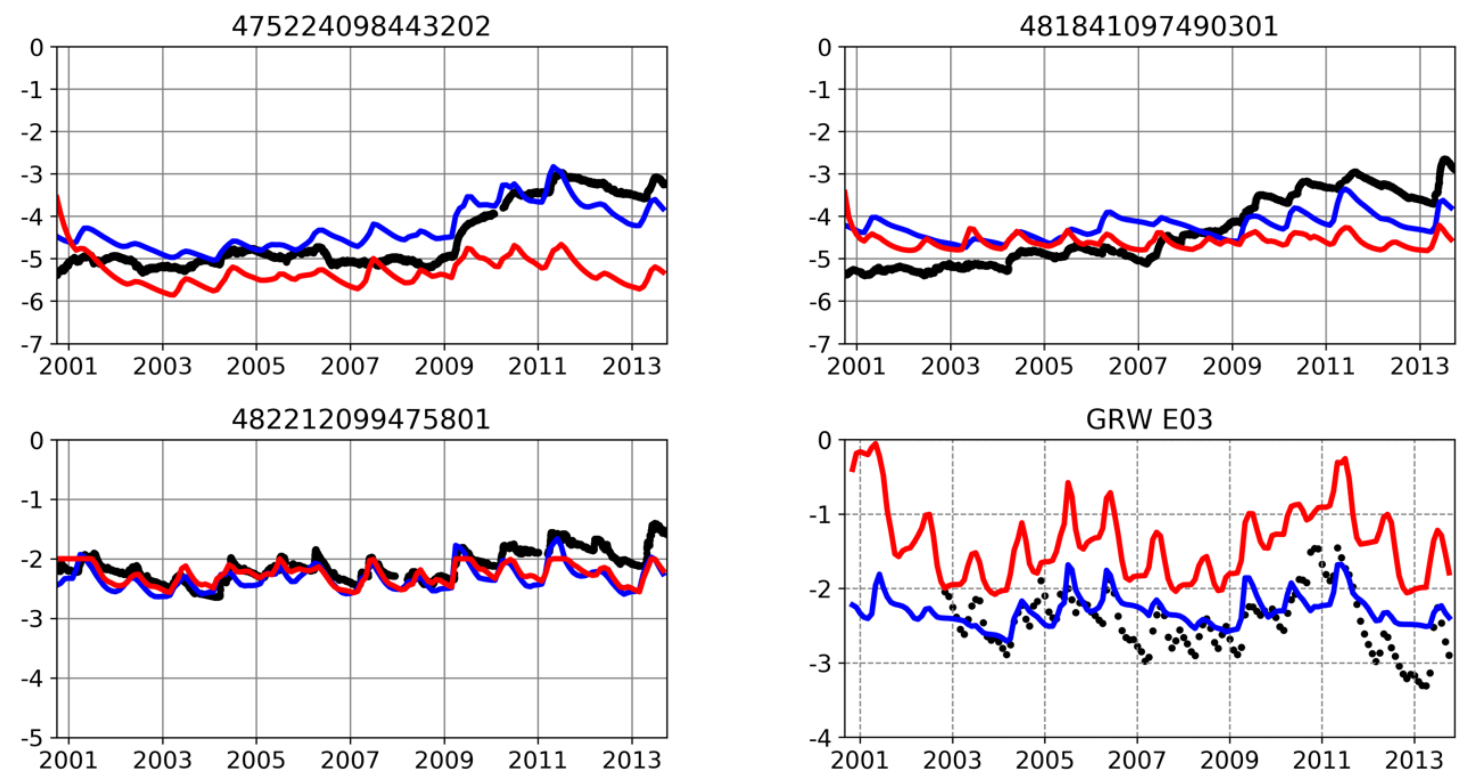